\title{
Gender differences and social ties effects in resource sharing
}

Citation for published version (APA):

d'Exelle, B., \& Riedl, A. (2016). Gender differences and social ties effects in resource sharing. Maastricht University, Graduate School of Business and Economics. GSBE Research Memoranda No. 023 https://doi.org/10.26481/umagsb.2016023

Document status and date:

Published: 01/01/2016

DOI:

10.26481/umagsb.2016023

Document Version:

Publisher's PDF, also known as Version of record

\section{Please check the document version of this publication:}

- A submitted manuscript is the version of the article upon submission and before peer-review. There can be important differences between the submitted version and the official published version of record.

People interested in the research are advised to contact the author for the final version of the publication, or visit the DOI to the publisher's website.

- The final author version and the galley proof are versions of the publication after peer review.

- The final published version features the final layout of the paper including the volume, issue and page numbers.

Link to publication

\footnotetext{
General rights rights.

- You may freely distribute the URL identifying the publication in the public portal. please follow below link for the End User Agreement:

www.umlib.nl/taverne-license

Take down policy

If you believe that this document breaches copyright please contact us at:

repository@maastrichtuniversity.nl

providing details and we will investigate your claim.
}

Copyright and moral rights for the publications made accessible in the public portal are retained by the authors and/or other copyright owners and it is a condition of accessing publications that users recognise and abide by the legal requirements associated with these

- Users may download and print one copy of any publication from the public portal for the purpose of private study or research.

- You may not further distribute the material or use it for any profit-making activity or commercial gain

If the publication is distributed under the terms of Article $25 \mathrm{fa}$ of the Dutch Copyright Act, indicated by the "Taverne" license above, 


\section{Maastricht University}

Ben D'Exelle, Arno Riedl

Gender differences and social ties effects in resource sharing

RM/16/023

\section{GSBE}

Maastricht University School of Business and Economics

Graduate School of Business and Economics

P.O Box 616

NL- 6200 MD Maastricht

The Netherlands 


\title{
Gender differences and social ties effects in resource sharing
}

\author{
Ben D'Exelle and Arno Riedl*
}

\begin{abstract}
In rural areas in developing countries gender inequality tends to be severe which might have substantial welfare implications if it determines how scarce economic resources are shared between men and women. Therefore, it is important to know how gender influences resource sharing and - given the strong embeddedness of resource sharing in social networks - in what ways social ties interact with this influence. To investigate this, we combine data from resource allocation experiments and a social network survey in rural Nicaragua. We find that women share less than men, and that this difference is largest among people of the same village and of different gender. We also find that social ties exert an important influence on sharing and that women have fewer friendship ties within their village than men. Regression analysis shows important gender differences in the effect of social ties on sharing. While both men and women share more with female friends than with female non-friends, women share less with male friends than with male non-friends. We also find that with controls for friendship ties, there remains a direct gender effect on within-village sharing, with men sharing more than women. Finally, we find that our results are robust to potential gender differences in the reporting of social ties.
\end{abstract}

Keywords: Resource sharing, social ties, gender, lab-in-the-field experiment, Nicaragua JEL Classification: C9, Z1

*Corresponding author: Ben D’Exelle, University of East Anglia, School of International Development, NR4 7TJ, Norwich, United Kingdom, b.dexelle@uea.ac.uk. 
Acknowledgements: The research documented in this article was financed by the Oesterreichische Nationalbank (project number 11429), VLIR-UOS, and IOB-UA. We thank participants in workshops, seminars, and conferences in Utrecht, Rome, Berlin, Nijmegen, Maastricht and Norwich for their valuable comments. We also benefited from comments on an earlier version of this article by Saurabh Arora, Rebecca Blank, Vincent Buskens, Simon Gächter, Jean Hagenbach, Matt Jackson, and Michael Woolcock. We also thank Guy Delmelle, Ligia Gómez, Miguel Alemán, Francisco Pérez, Selmira Flores and Alfredo Ruíz for interesting methodological discussions, Tania Paz Mena, Leonardo Matute, Francisco Paiz Salgado, Edna García Flores, Fátima Guevara, Silvia Martinez Arróliga and Will Tellez for support with the field work, Vanessa Castrillo and Jazmina Andino for their help in the search for sufficient coins of money, Elizabeth Campos and Manuel Bermudez of the Fondo de Desarrollo Local for offering a safe in one of their local banking offices, and the community leader Francisco Varela for his local support. 


\section{Introduction}

In rural villages in developing countries resource sharing is very common and strongly embedded in social networks. This is important for local welfare as well as the effectiveness of policies that aim to improve welfare (Ligon and Schechter, 2012). At the same time, in these villages gender inequality is ubiquitous and women tend to have a less favourable access to resources (World Bank, 2012). Given the economic and political importance of gender inequality, the importance of social networks for sharing and the role of sharing for welfare in rural villages, it is important to look more closely at the interaction between gender, social ties and resource sharing.

We start with the assumption that social proximity in networks increases sharing, for which there is growing empirical support (Leider et al., 2009; Goeree et al., 2010; Brañas-Garza et al., 2010; Ligon and Schechter, 2012), and we add a gender lens by addressing the following questions. First, to what extent can gender differences in sharing be explained by gender differences in social networks? Women tend to face more severe constraints, in terms of time poverty (Blackden and Wodon, 2006) and spatial mobility (Mandel, 2006; Hanson, 2010), both the result of the existing gendered division of labour. As a result, women may be socially less connected with others in their village, which in turn may lower their generosity towards others. There may also be considerable sorting on gender in the formation of social ties, which would lower sharing with people of different gender. Second, to what extent can gender differences in sharing be explained by gender differences in the valuation of friendship ties? The higher mobility and time constraints that women face may make it more difficult for them to take advantage of any social ties, which may lower their importance to them. Third, are there any gender differences in the reporting of friendship ties, which need to be taken into account? We know from recent studies that it is very common for responses to diverge when two people are asked about a possible relation between them (see, e.g., Comola and Fafchamps, 2014). It is important to take this into account, especially when such divergence may be correlated with gender.

To study these questions we surveyed almost all households in a rural village in Nicaragua 
and elicited the whole network of friendship ties of both spouses in every household (which for convenience we will call 'household heads'). After the survey we conducted a series of incentivised resource sharing experiments, using so-called 'dictator games'. In these games household heads (dictators) could share financial resources with randomly selected other villagers as well as non-anonymous strangers outside the village (recipients). Combining survey and experimental data we explore how the gender of the dictator and the recipient influence sharing decisions. To address question 1 , we test whether gender effects on resource sharing work directly or indirectly through the influence of gender on the formation of friendship ties by comparing regressions with and without controls for social ties. Question 2 is addressed by including interaction terms between gender matchings and reported friendship ties. For question 3 we exploit an important feature of our data, namely that we have perspectives from both nodes on the same dyad. This allows us to identify discordant reporting, and test whether it matters for the estimation of the effect of friendship ties on sharing across dyads of different gender combinations.

The results can be summarized as follows. First, women tend to share less than men, and this difference is largest when dictator and recipient live in the same village and have different gender. Second, these differences in sharing are in part driven by gender differences in the prevalence of social ties as women have on average fewer friendship ties within their village. Third, gender differences in sharing are also driven by the differential effect of social ties on sharing. More specifically, while both men and women share more with female friends than with female non-friends, women share less with male friends than with male non-friends. Fourth, when controlling for friendship ties, there remains a direct gender effect on sharing with people in the same village, with men sharing more than women. Finally, we find that our results are robust to potential gender differences in the reporting of social ties.

Several studies are related to ours. First, over the last three decades, there has been a burgeoning literature that uses experimental methods to study gender differences in resource sharing. Many of them used university subjects, and showed a large variety in outcomes, although contrary to our findings, none of them found women to be less generous than men. ${ }^{1}$ A growing number of studies have taken the lab to the field in developing countries, and many of them 
included gender controls in their analysis. The ones that used dictator games, as we do, did not find statistically significant gender effects (e.g. Binzel and Fehr (2013) in Cairo; Jakiela (2011) in Kenya; Gowdy et al. (2003) in Nigeria; Ligon and Schechter (2012) in Paraguay; Ado and Kurosaki (2014) in Jakarta). ${ }^{2}$ One exception is Gurven et al. (2008), who found that men in the Bolivian Amazone give more than women, which is consistent with our findings, but they did not give an explanation for this finding. Second, another line of experimental research has developed around how sharing is influenced by social proximity (Bohnet and Frey, 1999; Charness and Gneezy, 2008). Some of these studies have looked at the role of real-life social ties for resource sharing. Leider et al. (2009) found a positive effect of social proximity in social networks on resource sharing among students at a US university, a result replicated by Goeree et al. (2010) with teenage girls at a high school and Brañas-Garza et al. (2010) with undergraduate economics students in Spain, and recently extended to developing countries by Ligon and Schechter (2012) with villagers in rural Paraguay. ${ }^{3}$

The rest of the article is organised as follows. Section 2 describes our research design, including the social tie elicitation procedure and the procedures followed in the dictator game experiment. Section 3 presents the empirical analyses and section 4 discusses the results and concludes.

\section{Research design}

In the following we describe the main elements of our research design, which consists of a survey which elicits social ties, a standard survey that captures socio-economic characteristics, and a controlled resource sharing experiment. We also present some theoretical considerations.

\subsection{Data collection}

From all households in a rural village one randomly selected household head was selected to participate in a resource sharing experiment. More specifically, each participant played six subsequent so-called 'dictator games' with different recipients. The experimenter explained each participant who was in the role of a dictator that he or she would sequentially receive six small cylinder-boxes each containing 20 coins of one Córdoba, c\$ (the Nicaraguan currency), 
which he or she could (but need not) share with one other named person. For each dictator the first recipient was a stranger, that is, an unknown but named person from another village in the region. That the stranger was named allowed dictators to know the gender of the recipient. The five subsequent recipients were randomly selected village members.

The random selection involved the dictator drawing cards out of a bag containing all 123 household heads. Only after the dictator had finished the sharing decision regarding a recipient the name of the subsequent recipient was drawn. Dictators were informed of the procedures before they made any decision and, hence, knew that their maximum possible earnings would be c\$ 120,- (USD 6.70 at the time of the experiment). These potential earnings corresponded to more than a two days average income in Nicaragua. After explaining the instructions participants were given the opportunity to ask questions and if we identified that (part of) the instructions were unclear we provided additional explanations. This procedure made that all participants understood the instructions before making any decisions. ${ }^{4}$

We planned to conduct the experiment with all households in the village and had to make sure that the chance of contagion was minimized. Therefore, only one household head per household was allowed to participate as a dictator. In case of a two-headed household it was randomly determined who of the two was asked to participate. We did not exclude participation of the other household head in the role of recipient, but ensured that heads of the same household were not matched as a dictator-recipient pair.

Each dictator was made aware that, although he or she knew the identity of the recipient, the recipient did not know and also would not get to know from us who had given the money. When delivering the money to recipients we did neither reveal the identity of the dictator(s) who sent the money, nor did we inform them about how many dictators had participated. Dictators and recipients did also not learn anything about others' earnings. All this was known by the dictators when they made their decisions.

This one-way anonymity design provides some advantages over both a complete anonymous design, where receivers and dictators do not know each other's identity, and a full disclosure design, where receivers and dictators do know each other's identity. ${ }^{5}$ First, compared to complete anonymity, one-way anonymity enables dictators to take account of real-life socio- 
economic characteristics of the recipient, including gender, friendship ties and other important factors that may influence resource sharing. ${ }^{6}$ Second, compared to a full disclosure design, it is less likely that anticipated reciprocity and sanctions influence sharing decisions. In fact, in our design, resource sharing should be mainly influenced by (directed) altruism, which has been shown to be one of the most important drivers of sharing in friendship relations (Leider et al., 2009). ${ }^{7}$

We organized the experiment in a decentralized way, by having Nicaraguan research assistants visiting individual participants at their house to conduct the experiment. In doing so we deliberately deviated from the often used protocol in lab-in-the-field experiments, where experiments are often centrally conducted at a public spot. We did so for the following two reasons. First, we wanted to minimize selection bias. Organising the experiment at a public spot would open the door for self-selection as some people are reluctant to participate in public events, which might be correlated with their generosity and number of friendship ties. Second, during such gatherings mutual influence among participants is hard to control, and we anticipated that people's behaviour would be influenced by the identity of the other participants at such an event, including their gender. ${ }^{8}$

To minimize experimenter effects due to the assistant's presence we employed the following three precautionary measures. First, all decisions were made in full privacy. As a rule participants went inside their house or to a separate room and were, thus, out of sight of the assistant when making a decision. If this was not possible the assistant turned his or her back when the dictator was handling the coins. The dictators were also instructed not to make any comments about their decisions. Second, after having taken from the box the coins they wanted to keep, dictators had to fill the box with metal rings. This ensured that the weight of the box remained constant irrespective of the amount of coins taken out. Third, after each decision the box was sealed with tape. The decisions were recorded by the assistants' supervisor (one of the authors) who did not have any interaction with the participants. The dictators were made aware of these procedural details before they made any decisions. ${ }^{9}$

An important aspect in controlled experiments is that participants trust the researchers. This is not necessarily guaranteed when participants have no experience with economic experiments. 
Therefore, to build trust, we first conducted the household and social tie survey. This ensured that the research assistants were already known to the local people when they visited them for the experiment. Another important element was the support of the well-respected local community leaders, who at the start of the field research presented our team to each household and asked people to cooperate with the research team. By conducting the whole experiment in only one day we minimized possible contagion effects. We administered debriefing questions which showed that $94.5 \%$ of the participants did not talk about the experiment with other village members who had already participated before, hence contagion is virtually absent. In addition, the research assistants were asked to make a subjective evaluation about the participant's dedication, trust and understanding of the experiment. We did not notice any problems that could have affected the dictators' decisions.

The experiment was organised immediately after the surveys that captured basic socioeconomic data as well as social ties with other household heads from the same village. For the latter we adapted a survey method successfully employed by economic anthropologists and sociologists for mapping bounded networks. ${ }^{10,11}$ Specifically, to elicit the social ties of an interviewee we used a stack of small cards representing all households in the village. Each card held the name(s) of the head(s) of a household. For each of the cards the interviewee was first asked whether he or she knew the household. If they knew the household they were asked whether he or she had a "social relation of any kind" with (one of) the household head(s). If the answer was affirmative we asked for details on the content of the relation. The use of cards gave us an easy way to avoid any order bias in the elicitation of the ties, by reshuffling the cards at the start of every new interview. ${ }^{12}$

\subsection{Theoretical considerations}

To structure the analysis, we use the following model. Following Andreoni and Miller (2002) we assume that for each pair of players $i$ and $j$ the individual utility of player $i$ depends on the own pay-off $\pi_{i}$ and the pay-off of the matched player $j, \pi_{j}$. We assume that the pay-offs are directly determined by the distribution decision of player $i$ and that this decision remains unknown to $j$. Specifically, the pay-offs are determined by subject $i$ 's decision to keep $x$ out 
of an endowment $E$ for herself and to give the remainder $E-x$ to person $j$, to maximize her utility determined by the utility function $U_{i}\left(x, E-x ; \alpha_{i j}\right)$. The parameter $\alpha_{i j} \in[0,1]$ weighs the importance of the amount given to the recipient versus the amount kept $x$. The larger its value the more will be given to the matched recipient. It can be seen as a measure of $i$ 's altruism towards $j$ and consists of two components with $\alpha_{i j}=\alpha_{i}^{0}+\alpha_{i}^{1} P_{i j}$ and $\alpha_{i}^{0} \geq 0$ and $\alpha_{i}^{1} \geq 0$ (for a similar approach see eg. Leider et al. (2007)). The first component represents $i$ 's baseline altruism and the second measures $i$ 's directed altruism, with $P_{i j}$ being the social proximity between $i$ and $j$. It captures the idea that people tend to attribute a higher weight to the income of close others (Bohnet and Frey, 1999; Charness and Gneezy, 2008). In our setting we distinguish three levels of proximity: strangers (i.e. they live in a different village), acquaintances when they live in the same village but are not friends, and friends who live in the same village.

Importantly, we expect gender differences in $\alpha_{i}^{0}, \alpha_{i}^{1}$ and $P_{i j}$. First, there may be a gender difference in baseline altruism $\left(\alpha_{i}^{0}\right)$. In line with some of the experimental literature discussed above, baseline altruism may be larger for women than for men. However, the development economics literature suggests that women may get more utility out of keeping $x$ than men, which would make baseline altruism actually lower for women than for men, implying an opposite hypothesis. It has been documented that women have a stronger preference to spend resources on human capital, such as health, food related household consumption and their children (Thomas, 1990, 1993; Kennedv and Peters, 1992; Thomas, 1993; Hoddinott and Haddad, 1995; Phipps and Burton, 1998; Yoong et al., 2012; Dunbar et al., 2013). Such preference may make women share less than men with people outside their household.

Second, the directed altruism component $\alpha_{i}^{1} P_{i j}$ may also be different between men and women. $P_{i j}$ may differ if women, compared to men, are on average more socially distant from other people in their village, which in turn would make women share less with other people in their village. Women may be socially less connected with others in their village, as they tend to face more severe constraints in terms of time poverty (Blackden and Wodon, 2006) and spatial mobility (Mandel, 2006; Hanson, 2010), both the result of the existing gendered division of labour. There may also be considerable levels of sorting on gender in social ties as identified by 
some empirical studies (Attanasio et al., 2012; Bastani, 2007; Comola and Fafchamps, 2014; Marsden, 1987; Wellman, 2007; Stehl et al., 2013). In addition, $\alpha_{i}^{1}$ may differ across different gender combinations. The higher mobility and time constraints that women face may make it more difficult for them to take advantage of any social ties, which might lower their importance to them. Also, same-gender ties may be more valued than mixed-gender ties, as individuals who are similar are more likely to interact with each other (for a literature review on 'homophily' effects see McPherson et al., 2001)).

Each of these hypotheses will be tested using regressions that include social proximity, gender of the dictator and recipient, and interactions between social proximity and the gender of dictator and recipient as main explanatory variables. Any significant effect of the gender of the dictator and recipient in such regression suggests a gender difference in baseline altruism, i.e. our first hypothesis. To study the second hypothesis, regarding the role of $P_{i j}$, we will analyse gender differences in the prevalence of social ties and test whether controlling for social ties in the regressions captures any of the gender variation in sharing. The third hypothesis regarding the role of $\alpha_{i}^{1}$ and its interaction with gender, will be tested with the estimates of the interaction terms.

\section{Results}

In this section we present the empirical results. We start with a description of the study location, after which we present a descriptive analysis of the sharing decisions. Thereafter, we employ regression analysis to look into the influence of gender, friendship ties (and their interaction) on resource sharing. We end with several robustness tests.

\subsection{Location}

For this study we selected a village located in a rural area in the Northern part of the Pacific region of Nicaragua. It was purposively selected as it is representative for this area. The difficult agro-ecological conditions (dry season, irregular rainfall, low fertility of soils, etc.) make agricultural activities not very profitable in this region. Cattle breeding is one of the most lucrative economic activities because it is both an income source and an important savings 
instrument that enables local people to bridge the long and harsh dry season.

The village consists of 66 households of which 9 are single-headed and 57 two-headed. This size is similar to other villages in the area. Of the 123 household heads in total, 61 are male and 62 are female. We collected data on 58 households $(87.9 \%)$ and at least 100 household heads $(81.3 \%)$. Table 1 reports descriptive statistics of important socio-economic characteristics. It indicates a pronounced diversity across households as well as household heads. $34.48 \%$ of the households own land and land possession is unequally distributed, with the standard deviation being more than twice as large as the mean of 11.74 hectares. For cattle possession the figures are similar: $46.55 \%$ of all households possess cattle, and the average number of cattle per household is 3.55 with a standard deviation of 9.44 . We also calculated a wealth index equal to the first factor of a maximum likelihood factor analysis using economic assets such as land, cattle and the possession of tools/equipment which are good proxies for wealth in the region.

The second panel of the table summarizes individual characteristics of household heads, and the third panel summarizes individual and household characteristics of the household heads who participated as dictators in the experiment. Average education of household heads in the village, measured in number of years of schooling, is only slightly above 4 years with also quite some variation. Another potentially important characteristic is the number of years of residence in the village, the average of which is around 33 years. The average frequency of contact with the urban centre, which is important to obtain access to economic goods and services, is around 2 visits, as measured in the most recent month before our survey.

Average differences between men and women in the village on individual characteristics (not reported in the table) are as follows. Men are on average 5.71 years older than women ( $p=0.041$, two-sided $t$-test). This is in line with average age differences between husbands and wives in rural Nicaragua. Other differences are not statistically significant: education (average difference $=-0.74 ; p=0.290$, two-sided $t$-test), residence in village (average difference $=4.76$, $p=0.131$, two-sided $t$-test) and visits to urban centre (average difference $=1.06, p=0.117$, two-sided $t$-test). 
Table 1: Summary statistics of important socio-economic characteristics

\begin{tabular}{lrcc}
\hline \hline & mean/percentage & st.dev. & no. of obs. \\
\hline a. Households & & & \\
Land (percentage of owners) & 34.48 & - & 58 \\
Land (mean in ha.) & 11.74 & 24.76 & 58 \\
Cattle (percentage of owners) & 46.55 & - & 58 \\
Cattle (mean in no. of animals) & 3.55 & 9.44 & 58 \\
Wealth (index) & 0.00 & 1.75 & 58 \\
b. Household heads & & & \\
Gender (percentage male) & 49.50 & - & 109 \\
Age (mean in years) & 46.05 & 14.49 & 109 \\
Education (mean in years) & 4.13 & 3.59 & 109 \\
Residence in village (mean in years) & 33.22 & 15.63 & 100 \\
Visits to urban centre (mean no. last month) & 2.07 & 3.36 & 100 \\
c. Dictators & & & \\
Gender (percentage male) & 47.37 & - & 57 \\
Age (mean in years) & 44.16 & 12.78 & 57 \\
Wealth (index) & -0.07 & 1.65 & 57 \\
Education (mean in years) & 3.72 & 3.30 & 57 \\
Residence in village (mean in years) & 32.91 & 15.40 & 57 \\
Visits to urban centre (mean no. last month) & 2.10 & 2.61 & 57 \\
\hline \hline
\end{tabular}

\subsection{Descriptive analysis of sharing}

We start with a descriptive analysis of sharing decisions, and how they depend on the gender of the dictator and recipient. Then, we look at the role of social proximity, by studying whether it influences sharing, whether it correlates with gender, and whether its effect on sharing depends on gender.

\subsubsection{Sharing and gender}

Figure 1 presents the distribution of coins given to the recipient (including strangers and fellow villagers), disaggregated by the gender of the dictator. For both male and female dictators we observe large variation in allocations with a dominant mode at the equal split of 10 coins. These distributions indicate that women tend to share less resources than men. On average women leave 8.78 coins (st.dev. 4.68) and men leave 10.36 coins (st.dev. 4.65) to the recipient.

Intriguingly, there is a relatively large share of decisions where dictators leave more than 


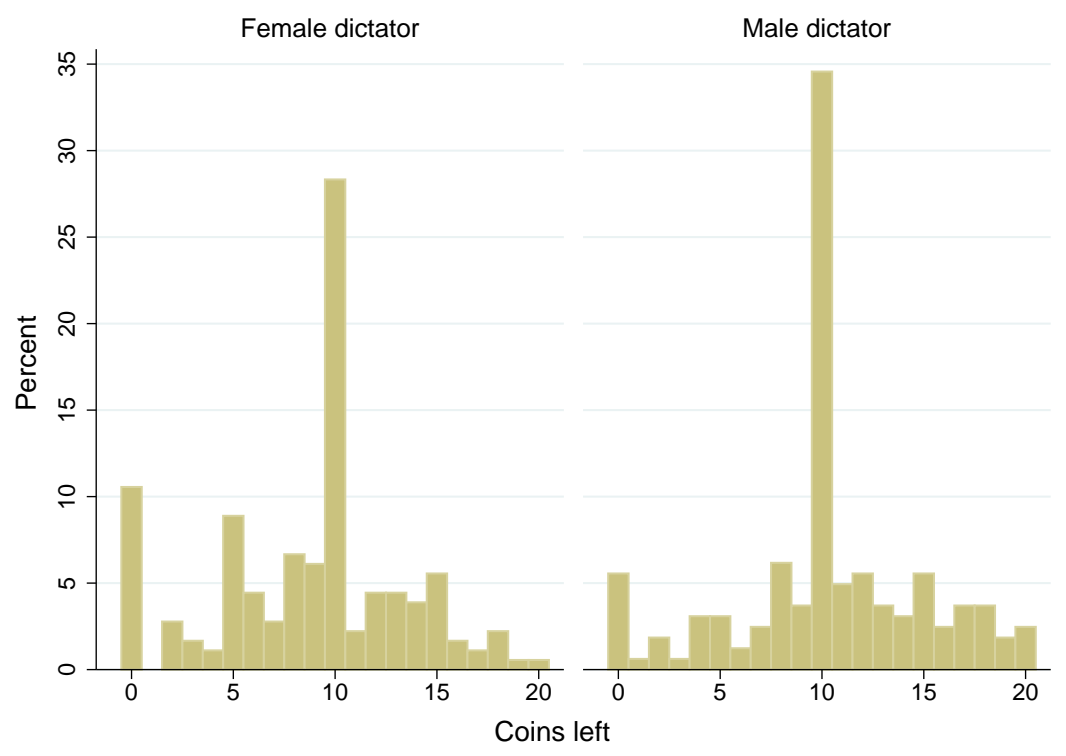

Figure 1: Resource sharing by gender of dictator

$50 \%$ of the coins to the recipient. Two factors may account for this generous behaviour. First, before taking a decision dictators were given the name of the recipient. ${ }^{13}$ Second, as in most small-scale societies, in this village most people know each other (based on our social ties data, in $93.5 \%$ of all possible ties the other was known).

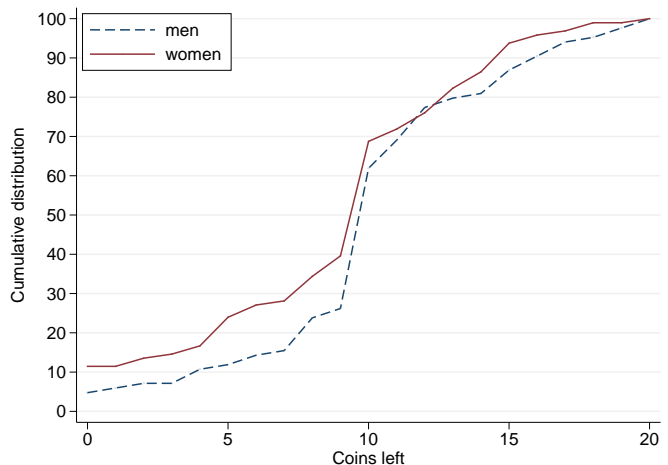

(a) Same gender

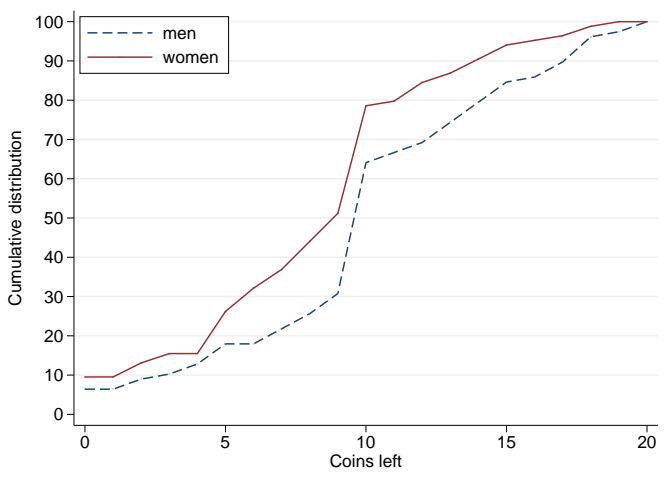

(b) Different gender

Figure 2: Resource sharing by gender of dictator and recipient

In a next step, we take the gender of the recipient into account. Figure 2 shows the cumulative distributions of resource sharing of male and female dictators for same gender pairs (panel a) and different gender pairs (panel b). These distributions again indicate that women tend to share less than men do, and that the differences become stronger when the dictator and 
recipient have different gender, as a comparison of both panels shows.

Table 2: Sharing by gender combination

\begin{tabular}{lccccc}
\hline \hline & \multicolumn{3}{c}{ women } & \multicolumn{2}{c}{ men } \\
& mean & $\mathrm{N}$ & mean & $\mathrm{N}$ & p-value \\
\hline a. All pairs & & & & & \\
same gender & 9.09 & 96 & 10.39 & 84 & 0.204 \\
different gender & 8.42 & 84 & 10.33 & 78 & 0.117 \\
\hline b. Same village pairs & & & & & \\
same gender & 9.19 & 80 & 10.55 & 67 & 0.190 \\
different gender & 8.16 & 70 & 10.63 & 68 & $0.042^{* *}$ \\
\hline \hline
\end{tabular}

Notes: t-test with standard errors corrected for multiple decisions per dictator. ${ }^{* * *},{ }^{* *},{ }^{*}$ indicate two-sided significance levels at 1,5 , and $10 \%$, respectively.

To test whether average sharing differs between male and female dictators, and whether it depends on the gender of the recipient, we use a two-tailed t-test. Table 2 presents the results. Using all dictator-recipient pairs (panel (a)) we find that male dictators tend to share more than female dictators, in both same gender and different gender pairs. Based on the p-values, however, we cannot reject the hypothesis of no difference in sharing. Using pairs of dictators and recipients who live in the same village we find that the difference in sharing between men and women is statistically significant with different gender pairs.

\subsubsection{The role of social proximity}

The fact that we only find significant gender differences in sharing with pairs of the same village suggests that the effect of gender interacts with social proximity between dictator and recipient. Social proximity differs depending on whether dictator and recipient live in the same village, and if they live in the same village whether they have a friendship tie. While the first source of variation is exogenously determined by our experimental design, variation in friendship ties is endogenous, and may be correlated with gender.

As discussed before, there are two important ways in which social proximity can interact with gender. First, if social proximity influences sharing - as several studies have demonstrated - and at the same time correlates with gender, gender differences in sharing may be caused by gender differences in social proximity. For example, women may be less generous than 
men if they have fewer social ties with other people in their village than men. Second, the influence of social proximity on sharing itself may depend on the gender of the dictator and recipient. To get a first idea of whether our data support these mechanisms, we will look at each of these conditions. More specifically, we will have a closer look at whether: 1) social proximity influences sharing; 2) social proximity correlates with gender; and 3) the effect of social proximity on sharing depends on gender.

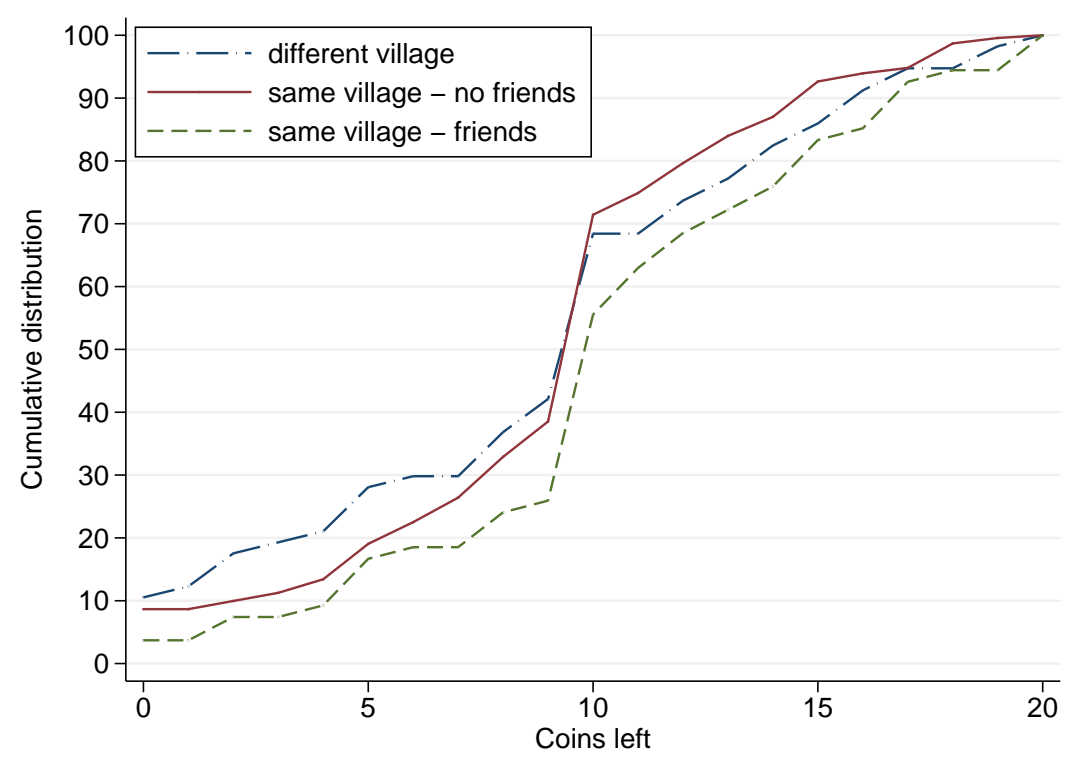

Figure 3: Sharing by social proximity

In a first step, we study whether social proximity, via social ties and living in the same village, influences sharing. Overall we gathered social ties data for 100 of the 123 household heads $(81.3 \%) .{ }^{14}$ As explained before, we asked each household head whether he or she had a friendship tie with the other household heads, for each household in the village. We use friendship ties as OR-ties, i.e. we symmetrize the social ties by assuming that a friendship relation exists if at least one node mentions the relation. ${ }^{15}$ Figure 3 shows how the distribution of coins left to the recipient differs between different levels of social proximity. We observe that the distribution of coins left to friends is skewed towards higher generosity compared to the distributions of coins left to non-friends that live in the same village and to strangers. Based on a two-tailed t-test both differences are marginally statistically significant (two-sided $\mathrm{p}=0.099$ and 0.073 , respectively). 
Table 3: Summary statistics of friendship ties

\begin{tabular}{lcc}
\hline \hline & freq. & $\mathrm{N}$ \\
Male-only dyads & $31.72 \%$ & 1,693 \\
Female-only dyads & $12.51 \%$ & 1,870 \\
Mixed gender dyads & $12.95 \%$ & 3,613 \\
\hline
\end{tabular}

In a second step we test whether social proximity via social ties correlates with gender. Table 3 reports the frequency of friendship ties. We observe that friendship ties are more common among male-only dyads than among female-only dyads or mixed gender dyads. Based on a two-tailed t-test this difference is statistically significant (two-sided $p=0.000$ for each comparison). The frequency of friendship ties is not statistically different between mixed gender dyads and female-only dyads (two-sided $\mathrm{p}=0.644$ ).

Table 4: Sharing by social proximity

\begin{tabular}{|c|c|c|c|c|c|}
\hline \multirow[t]{2}{*}{$\overline{\text { Panel a. }}$} & \multicolumn{2}{|c|}{ stranger } & \multicolumn{2}{|c|}{ non-friend } & \multirow[b]{2}{*}{$\mathrm{p}$-value } \\
\hline & mean & $\mathrm{N}$ & mean & $\mathrm{N}$ & \\
\hline all & 9.18 & 57 & 9.32 & 231 & 0.794 \\
\hline men & 9.22 & 27 & 10.15 & 100 & 0.195 \\
\hline women & 9.13 & 30 & 8.69 & 131 & 0.589 \\
\hline \multirow[t]{2}{*}{ Panel b. } & \multicolumn{2}{|c|}{ non-friend } & \multicolumn{2}{|c|}{ friend } & \\
\hline & mean & $\mathrm{N}$ & mean & $\mathrm{N}$ & $\mathrm{p}$-value \\
\hline all & 9.32 & 231 & 10.80 & 54 & $0.099^{*}$ \\
\hline men & 10.15 & 100 & 11.86 & 35 & $0.083^{*}$ \\
\hline women & 8.69 & 131 & 8.84 & 19 & 0.922 \\
\hline \multirow[t]{2}{*}{ Panel c. } & \multicolumn{2}{|c|}{ stranger } & \multicolumn{2}{|c|}{ friend } & \\
\hline & mean & $\mathrm{N}$ & mean & $\mathrm{N}$ & $\mathrm{p}$-value \\
\hline all & 9.18 & 57 & 10.80 & 54 & $0.073^{*}$ \\
\hline men & 9.22 & 27 & 11.86 & 35 & $0.013^{* *}$ \\
\hline women & 9.13 & 30 & 8.84 & 19 & 0.858 \\
\hline
\end{tabular}

Notes: t-test with standard errors corrected for multiple decisions per dictator. ${ }^{* * *},{ }^{* *},{ }^{*}$ indicate two-sided significance levels at 1,5 , and $10 \%$, respectively.

In a final step we test whether the influence of social proximity depends on the gender of the dictator. For this we use a two-tailed t-test. Table 4 presents the results. In panel (a) we compare average sharing between recipients from a different village (strangers) and recipients from the same village who are non-friends. Differences are not statistically significant. This 
is also the case when we disaggregate by the gender of the dictator. Comparing average sharing between recipients who are friends and non-friends from the same village (panel (b)) we only find a marginally significant difference for male dictators. Male dictators share on average 11.86 coins to friends and 10.15 to non-friends. Finally, comparing average sharing between friends and strangers (panel (c)) we again find a significant difference with male dictators (which is now statistically significant at the 5\% level), but not with female dictators. We summarize the main observations of the descriptive analyses in a first result.

RESULT 1. (a) Women tend to share less than men. This difference is strongest when dictator and recipient live in the same village and have different gender. (b) Social proximity positively influences generosity of male dictators. (c) Friendship ties are more common among men than among women and mixed gender dyads.

\subsection{Regression analysis: entire sample}

In this section we will use regression analysis to obtain a more complete picture of the influence of social proximity and gender on sharing, taking into account all possible interactions. ${ }^{16}$ It also allows us to control for any confounding factors that might have influenced sharing, including observable and unobservable characteristics of the dictator and the recipient. More specifically, we will use the following econometric specification:

$$
\begin{aligned}
y_{i j} & =\beta_{0}+\beta_{1} \delta_{i}+\beta_{2} \delta_{j}+\beta_{3} \delta_{i} \cdot \delta_{i}+\beta_{4} P(1)_{i j}+\beta_{5} P(2)_{i j}+\beta_{6} \delta_{i} \cdot P(1)_{i j}+\beta_{7} \delta_{i} \cdot P(2)_{i j} \\
& +\beta_{8} \delta_{j} \cdot P(1)_{i j}+\beta_{9} \delta_{j} \cdot P(2)_{i j}+\beta_{10} \delta_{i} \cdot \delta_{j} \cdot P(1)_{i j}+\beta_{11} \delta_{i} \cdot \delta_{j} \cdot P(2)_{i j}+\sigma_{i}+\varepsilon_{i j}
\end{aligned}
$$

where $y_{i j}$ denotes the amount of coins dictator $i$ leaves to recipient $j . \delta_{i}$ and $\delta_{j}$ are dummies that denote the gender of the dictator and the recipient, respectively, being equal to one if male. $P(1)_{i j}$ and $P(2)_{i j}$ are dummies equal to one if the dictator and recipient live in the same village and are not friends $\left(P(1)_{i j}\right)$, and are friends $\left(P(2)_{i j}\right)$. The comparison category is $P(0)_{i j}$, equal to one if dictator and recipient are strangers to each other (i.e. they live in a different village). While the constant term estimates sharing with female strangers by female dictators, the gender 
dummies allow us to estimate sharing with strangers for the other three gender combinations. The social proximity dummies allow us to estimate the influence of social proximity for femalefemale dyads, while to estimate its effect for the other three gender combinations we use the interaction terms.

Exploiting the within-subject design, $\sigma_{i}$ is the time-invariant error, which captures observable and unobservable characteristics of dictators (i.e. that remain fixed across all their decisions). It also controls for potential experimenter bias (we used five different experimenters), including the gender of the experimenter, which might influence the dictators' decisions. $e_{i j}$ captures any remaining idiosyncratic error.

We will run different versions of this specification. We will start with a basic model that only includes the gender dummies and their interaction. In a next step we include the social proximity dummies and in a final step also the interaction between the social proximity and the gender dummies. This stepwise approach allows us to test the robustness of direct gender effects, and whether they work via a direct effect or indirectly via social tie formation. The latter would be supported by the finding that any significant gender effects in the basic model disappear once we control for social proximity.

We will run all models with and without dictator fixed effects to investigate the robustness of the results to controls for observable and unobservable characteristics of the dictator. In addition, as each dictator performed sharing-decisions regarding five different village recipients, the observations cannot be assumed to be independent. In particular, we have that $E\left[e_{i j}, e_{i k}\right] \neq 0$ for all $k$. For this reason, we will cluster standard errors at the level of the individual dictators.

Table 5 presents the results of the different models. In Models 1-4 we do not find any statistically significant gender effects. In Models 3 and 4 we find that the coefficient of $\mathrm{P}(2)$ is positive, but only marginally significant when using dictator fixed effects (model 4). On average dictators tend to leave 1.3 coins more to recipients if they are friends. This positive effect is robust to adding interaction terms between social proximity and gender (Models 5 and 6). In Model 5 we also observe that the coefficient of the interaction 'Male (rec.) $\times \mathrm{P}(2)$ ' is negative and highly significant, which is robust to the use of fixed effects, as we observe in Model 6. 
Table 5: Determinants of sharing

\begin{tabular}{|c|c|c|c|c|c|c|}
\hline & (1) & (2) & (3) & (4) & (5) & (6) \\
\hline \multirow[t]{2}{*}{ Male (dict.) } & 1.240 & & 1.213 & & -0.325 & \\
\hline & $(1.225)$ & & (1.207) & & (2.136) & \\
\hline \multirow[t]{2}{*}{ Male (rec.) } & -0.677 & -0.607 & -0.629 & -0.559 & 1.089 & 0.730 \\
\hline & $(0.572)$ & $(0.541)$ & $(0.578)$ & $(0.538)$ & (2.043) & $(1.535)$ \\
\hline \multirow[t]{2}{*}{ Male (dict.) $\times$ Male $($ rec.) } & 0.737 & 0.893 & 0.538 & 0.681 & 0.375 & -1.582 \\
\hline & $(0.807)$ & $(0.657)$ & $(0.850)$ & $(0.667)$ & (2.909) & $(1.976)$ \\
\hline \multirow[t]{2}{*}{$\mathrm{P}(1)$} & & & 0.201 & 0.221 & 0.110 & -0.148 \\
\hline & & & $(0.562)$ & $(0.541)$ & $(1.461)$ & (1.254) \\
\hline \multirow[t]{2}{*}{$\mathrm{P}(2)$} & & & 1.350 & $1.335^{*}$ & $3.125^{* *}$ & $2.972^{*}$ \\
\hline & & & $(0.877)$ & $(0.667)$ & (1.456) & $(1.491)$ \\
\hline \multirow[t]{2}{*}{ Male (dict. $) \times \mathrm{P}(1)$} & & & & & 1.748 & 0.677 \\
\hline & & & & & (2.030) & $(1.541)$ \\
\hline \multirow[t]{2}{*}{ Male (dict.) $\times \mathrm{P}(2)$} & & & & & 1.666 & -2.457 \\
\hline & & & & & (2.513) & $(1.702)$ \\
\hline \multirow[t]{2}{*}{ Male $($ rec. $) \times \mathrm{P}(1)$} & & & & & -1.190 & -1.063 \\
\hline & & & & & $(2.220)$ & (1.606) \\
\hline \multirow[t]{2}{*}{ Male $($ rec. $) \times \mathrm{P}(2)$} & & & & & $-8.982^{* * *}$ & $-4.869^{* * *}$ \\
\hline & & & & & $(2.863)$ & $(1.723)$ \\
\hline \multirow[t]{2}{*}{ Male (dict.) $\times$ Male $($ rec. $) \times \mathrm{P}(1)$} & & & & & -0.293 & 2.261 \\
\hline & & & & & (3.264) & (2.174) \\
\hline \multirow[t]{2}{*}{ Male $($ dict. $) \times$ Male $($ rec. $) \times \mathrm{P}(2)$} & & & & & 5.718 & $6.837^{* * * *}$ \\
\hline & & & & & (3.927) & (2.373) \\
\hline \multirow[t]{3}{*}{ Constant } & $9.094^{* * * *}$ & $9.608^{* * * *}$ & $8.783^{* * * *}$ & $9.276^{* * *}$ & $8.625^{* * *}$ & $9.250^{* * * *}$ \\
\hline & $(0.768)$ & $(0.161)$ & $(0.905)$ & $(0.485)$ & (1.441) & $(0.684)$ \\
\hline & OLS & $\overline{\mathrm{FE}}$ & OLS & $\mathrm{FE}$ & OLS & FE \\
\hline Observations & 342 & 342 & 342 & 342 & 342 & 342 \\
\hline$R^{2}$ & 0.031 & 0.008 & 0.039 & 0.030 & 0.087 & 0.076 \\
\hline $\mathrm{F}$ & 1.521 & 0.924 & 1.401 & 1.952 & 3.730 & 3.504 \\
\hline
\end{tabular}

To better understand the effect of social proximity and gender combinations we use the results of Model 5 to estimate sharing predictions, which are presented in Table 6 , ${ }^{17}$ Panel (a) presents predicted sharing by social proximity and gender combination. We observe that social proximity increases generosity for all gender combinations, except F-M. At the same time, differences across gender combinations are small, except for $\mathrm{P}(2)$, i.e. in which dictator and recipient are friends. Panel (b) tests whether differences in sharing across the different gender combinations are statistically different from zero. With $\mathrm{P}(0)$ differences are not significant, which implies that baseline altruism does not depend on the gender of the dictator and recipient. Differences are only significant with $\mathrm{P}(2)$. Sharing is significantly lower with F-M than with each of the other gender combinations.

In a next step we take a closer look at the marginal effects of social proximity for the different gender combinations. In panel (a) of Table 7 we observe that with male-male dyads dictators tend to give 1.7 coins more to recipients from the same village who are not friends relative to strangers, and nearly 2.5 more to friends from the same village. Male dictators 
Table 6: Predicted sharing by gender combination and social proximity

\begin{tabular}{lcccc}
\hline \hline & & & & \\
(a) Predicted sharing & & & & \\
$\mathrm{P}(0)$ & $\mathrm{M}-\mathrm{M}$ & $\mathrm{M}-\mathrm{F}$ & $\mathrm{F}-\mathrm{F}$ & $\mathrm{F}-\mathrm{M}$ \\
$\mathrm{P}(1)$ & 9.76 & 8.30 & 8.63 & 9.71 \\
$\mathrm{P}(2)$ & 10.14 & 10.16 & 8.74 & 8.63 \\
& 11.29 & 13.09 & 11.75 & 3.86 \\
\hline
\end{tabular}

\begin{tabular}{|c|c|c|c|c|}
\hline (b) $P c$ & across \& & ender & mbinati & $s^{\mathrm{a}}$ \\
\hline & & M-F & F-F & F-M \\
\hline & M-M & 0.482 & 0.565 & 0.980 \\
\hline $\mathrm{P}(0)$ & M-F & & 0.880 & 0.511 \\
\hline & F-F & & & 0.596 \\
\hline & & M-F & F-F & F-M \\
\hline & M-M & 0.976 & 0.541 & 0.155 \\
\hline $\mathrm{P}(1)$ & $\mathrm{M}-\mathrm{F}$ & & 0.540 & 0.169 \\
\hline & $\mathrm{F}-\mathrm{F}$ & & & 0.908 \\
\hline & & M-F & F-F & F-M \\
\hline & M-M & 0.254 & $0.067^{*}$ & $0.000^{* * *}$ \\
\hline $\mathrm{P}(2)$ & M-F & & 0.482 & $0.001^{* * * *}$ \\
\hline & F-F & & & $0.000^{* * * *}$ \\
\hline
\end{tabular}

Note. Regression results used of Model 5 of Table $5{ }^{* * *},{ }^{* *},{ }^{*}$ indicate twosided significance levels of an F-test at 1,5 , and $10 \%$, respectively. ${ }^{\text {a }}$ Two-sided p-values.

Table 7: Marginal effects of social proximity

\begin{tabular}{|c|c|c|c|c|}
\hline \multicolumn{5}{|c|}{ (a) Marginal effect by gender combination } \\
\hline & M-M & M-F & F-F & F-M \\
\hline $\mathrm{P}(1)$ & $1.726^{*}$ & 0.528 & -0.148 & -1.211 \\
\hline $\mathrm{P}(2)$ & $2.485^{* *}$ & 0.516 & $2.972^{*}$ & $-1.896^{*}$ \\
\hline \multicolumn{5}{|c|}{ (b) Pairwise comparison across gender combinations a } \\
\hline \multirow{4}{*}{$\mathrm{P}(1)$} & & M-F & F-F & F-M \\
\hline & M-M & 0.417 & 0.250 & $0.040^{* *}$ \\
\hline & $\mathrm{M}-\mathrm{F}$ & & 0.662 & 0.190 \\
\hline & $\mathrm{F}-\mathrm{F}$ & & & 0.511 \\
\hline \multirow{4}{*}{$\mathrm{P}(2)$} & & $\mathrm{M}-\mathrm{F}$ & $\mathrm{F}-\mathrm{F}$ & F-M \\
\hline & M-M & 0.232 & 0.801 & $0.007^{* * *}$ \\
\hline & M-F & & 0.155 & $0.067^{*}$ \\
\hline & $\mathrm{F}-\mathrm{F}$ & & & $0.007^{* * * *}$ \\
\hline
\end{tabular}

Note. Regression results used of Model 6 of Table [5] ***, **, * indicate twosided significance levels of an F-test at 1, 5, and 10\%, respectively. ${ }^{\text {a }}$ Two-sided p-values 
do not seem to take social proximity into account when paired with a female recipient. Women tend to be more generous towards female friends of the same village, but not towards non-friends of the same village. They tend to give nearly 3 coins more to female friends than to female strangers. Finally, women give less to male recipients from their village. They tend to give nearly 1.9 coins less to male friends than to male strangers. Panel (b) presents the results of a pairwise comparison of the marginal effects across the different gender combinations, using an F-test. The marginal effect of ' $\mathrm{P}(1)$ ' is only statistically different between $\mathrm{M}-\mathrm{M}$ and F-M. The marginal effect of ' $\mathrm{P}(2)$ ', is statistically different between F-M and each of the other gender combinations. We summarize the main observations in a new result.

RESULT 2. Men share more with men from their village than with male strangers. Women share more with female friends than with female strangers and share less with male friends than with male strangers. Differences in the effect of social proximity are statistically significant between female-male dyads and all other gender combinations.

\subsection{Regression analysis: same village sample}

In a next step we run the same models using only the same village pairs. This has three advantages. First, it allows us to analyse possible order effects, second, we can use recipient fixed effects to control for any observed and unobserved characteristics of the recipient, and third, focusing on within-village variation in sharing could generate new insights. ${ }^{18}$ More specifically, we will make the following changes to the specifications used in the previous section. Using only the sample of same village pairs, we use $\mathrm{P}(1)$ as base category. We add dummy variables to control for order effects, and in an alternative model we use recipient fixed effects instead of dictator fixed effects. Table 8 presents the results of the different models.

First of all, we find that none of the coefficients of the order dummies are statistically significant, except the coefficient of decision 5 which is marginally significant in models 1,2 , 4 and 5. The coefficients suggest that in the final decision dictators are somewhat less generous compared to the first decision when paired with a recipient from the same village, and that the order does not exert any influence at all between decisions 2 and 5. This supports the claim that 
order effects are limited.

Looking at the direct gender effects, we observe in Models 1 and 2 that several of them are now statistically significant (remember that we now use a different base category). Model 1 tells us that male recipients tend to receive on average around one coin less than female recipients. Controlling for dictator fixed effects (Model 2) we find that this negative effect is absent with male dictators, as indicated by the size of the coefficient of 'Male (dict.) $\times$ Male (rec.)'. So, only female dictators treat male recipients less generously. Using recipient fixed effects (Model 3) we find that recipients of the same village tend to receive around two coins more from male dictators than from female dictators. In Models 4, 5 and 6 the coefficient of ' $\mathrm{P}(2)$ ' is positive, but only when using dictator or recipient fixed effects (models 5 and 6 ) is it (marginally) significant.

Table 8: Determinants of sharing (same village sample)

\begin{tabular}{|c|c|c|c|c|c|c|c|c|c|}
\hline & (1) & (2) & (3) & (4) & (5) & (6) & (7) & (8) & (9) \\
\hline \multirow[t]{2}{*}{ Male (dict.) } & 1.445 & & $2.129^{* *}$ & 1.434 & & $2.139^{* *}$ & 1.407 & & $2.022^{* *}$ \\
\hline & $(1.243)$ & & $(0.893)$ & (1.219) & & $(0.828)$ & $(1.241)$ & & $(0.888)$ \\
\hline \multirow[t]{2}{*}{ Male (rec.) } & $-1.002^{*}$ & -0.737 & & -0.951 & -0.701 & & -0.099 & -0.292 & \\
\hline & $(0.585)$ & $(0.503)$ & & $(0.609)$ & $(0.502)$ & & $(0.675)$ & $(0.596)$ & \\
\hline \multirow[t]{2}{*}{ Male $($ dict. $) \times$ Male $($ rec. $)$} & 0.949 & $1.394^{*}$ & -0.475 & 0.677 & 1.149 & -0.978 & 0.092 & 0.721 & -1.320 \\
\hline & $(0.913)$ & $(0.701)$ & $(1.376)$ & $(0.995)$ & $(0.703)$ & $(1.431)$ & $(0.909)$ & $(0.789)$ & $(1.512)$ \\
\hline \multirow[t]{2}{*}{$\mathrm{P}(2)$} & & & & 1.088 & $0.862^{*}$ & $1.787^{*}$ & $2.904^{* * * *}$ & $2.701^{* *}$ & $4.308^{* * *}$ \\
\hline & & & & $(0.885)$ & $(0.479)$ & $(1.002)$ & $(1.066)$ & $(1.165)$ & $(0.889)$ \\
\hline \multirow[t]{2}{*}{ Male (dict.) $\times \mathrm{P}(2)$} & & & & & & & 0.048 & $-2.445^{*}$ & 0.902 \\
\hline & & & & & & & (1.927) & $(1.392)$ & (2.705) \\
\hline \multirow[t]{2}{*}{ Male $($ rec. $) \times \mathrm{P}(2)$} & & & & & & & $-7.643^{* * *}$ & $-3.610^{* *}$ & $-9.078^{* * *}$ \\
\hline & & & & & & & $(1.971)$ & (1.389) & (2.099) \\
\hline \multirow[t]{2}{*}{ Male (dict.) $\times$ Male $($ rec. $) \times \mathrm{P}(2)$} & & & & & & & $5.855^{* *}$ & $4.028^{* *}$ & 5.195 \\
\hline & & & & & & & $(2.449)$ & $(1.626)$ & (3.793) \\
\hline \multirow[t]{2}{*}{ Decision 2} & -0.581 & -0.561 & -0.653 & -0.609 & -0.584 & -0.530 & -0.513 & -0.517 & -0.225 \\
\hline & $(0.490)$ & $(0.485)$ & $(1.310)$ & $(0.498)$ & (0.491) & $(1.248)$ & $(0.517)$ & $(0.476)$ & $(1.232)$ \\
\hline \multirow[t]{2}{*}{ Decision 3} & -0.559 & -0.598 & 0.120 & -0.497 & -0.547 & 0.292 & -0.425 & -0.436 & 0.189 \\
\hline & $(0.546)$ & $(0.538)$ & (1.007) & $(0.555)$ & $(0.540)$ & (1.009) & $(0.548)$ & $(0.530)$ & $(0.952)$ \\
\hline \multirow[t]{2}{*}{ Decision 4} & -0.545 & -0.551 & 0.043 & -0.514 & -0.527 & 0.158 & -0.444 & -0.420 & 0.193 \\
\hline & $(0.443)$ & $(0.443)$ & $(1.286)$ & $(0.444)$ & $(0.440)$ & $(1.261)$ & $(0.452)$ & $(0.424)$ & (1.199) \\
\hline \multirow[t]{2}{*}{ Decision 5} & $-0.839^{*}$ & $-0.886^{*}$ & -0.654 & $-0.791^{*}$ & $-0.846^{*}$ & -0.605 & -0.607 & -0.696 & -0.555 \\
\hline & $(0.464)$ & $(0.454)$ & $(1.219)$ & $(0.468)$ & $(0.455)$ & $(1.201)$ & $(0.479)$ & $(0.447)$ & (1.108) \\
\hline \multirow{3}{*}{ Constant } & $9.679^{\text {**** }}$ & $10.146^{* * * *}$ & $8.932^{* * * *}$ & $9.495^{\text {*** }}$ & $10.004^{* * * *}$ & $8.615^{\text {*** }}$ & $9.140^{* * *}$ & $9.827^{\text {*** }}$ & $8.655^{* * * *}$ \\
\hline & $(0.836)$ & $(0.383)$ & $(0.828)$ & $(0.854)$ & $(0.394)$ & $(0.795)$ & $(0.969)$ & $(0.398)$ & $(0.789)$ \\
\hline & OLS & dict. FE & rec. FE & OLS & dict. FE & rec. FE & OLS & dict. FE & rec. FE \\
\hline Observations & 285 & 285 & 285 & 285 & 285 & 285 & 285 & 285 & 285 \\
\hline$R^{2}$ & 0.053 & 0.036 & 0.047 & 0.061 & 0.051 & 0.067 & 0.108 & 0.077 & 0.140 \\
\hline $\mathrm{F}$ & 1.916 & 3.431 & 1.485 & 2.367 & 3.277 & 1.953 & 3.641 & 4.047 & 5.932 \\
\hline
\end{tabular}

Notes: OLS regression. ${ }^{* * *},{ }^{* *},{ }^{*}$ indicate two-sided significance levels at 1,5 , and $10 \%$, respectively; standard errors (in parentheses) clustered at the dictator level, except models 3,6 and 9 in which they are clustered at the recipient level.

In Models 7, 8 and 9 we include interaction terms between the existence of a friendship tie and the gender dummies. In Model 7 the coefficients of ' $\mathrm{P}(2)$ ', 'Male (rec.) $\times \mathrm{P}(2)$ ' and 'Male (dict.) $\times$ Male (rec.) $\times \mathrm{P}(2){ }^{\prime}$ are all highly significant. Using dictator fixed effects (Model 
8) the same coefficients remain statistically significant, and now also the coefficient of 'Male (dict.) $\times \mathrm{P}(2)$ ' becomes marginally statistically significant. In Model 9, which uses recipient fixed effects, we find that the coefficients of ' $\mathrm{P}(2)$ ' and 'Male (rec.) $\times \mathrm{P}(2)$ ' remain statistically significant, and that also the coefficient of 'Male (dict.)' is again statistically significant.

Table 9: Predicted sharing by gender combination and social proximity

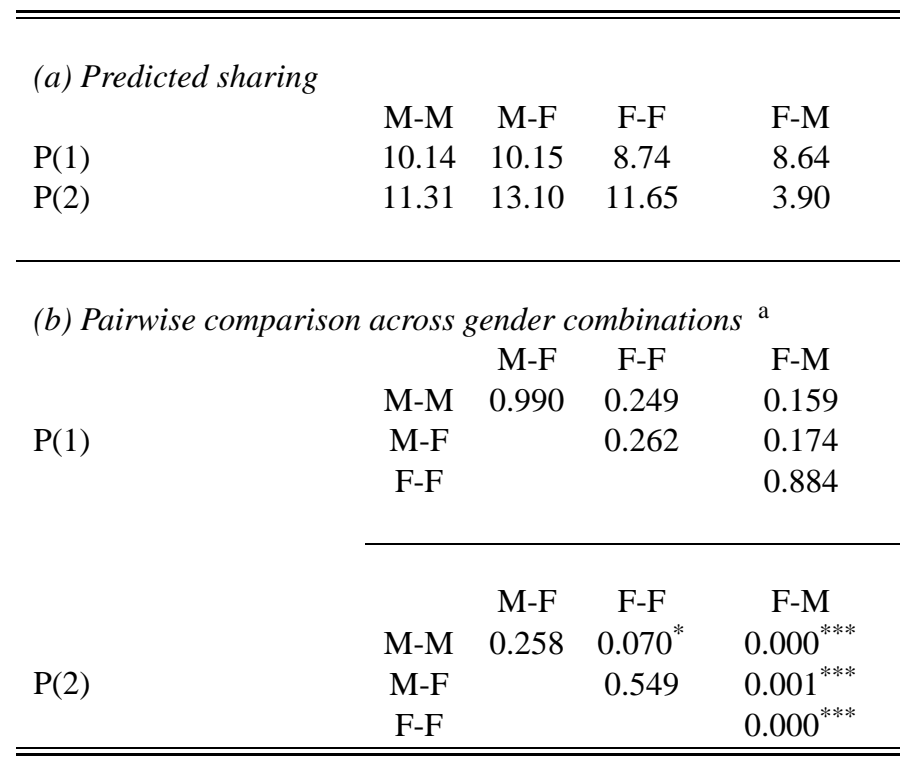

Note. Regression results used of Model 7 of Table $8 . * *,{ }^{* *},{ }^{*}$ indicate twosided significance levels of an F-test at 1, 5, and 10\%, respectively. ${ }^{\text {a }}$ Two-sided p-values.

To better understand the estimated effects, we again estimate sharing predictions for different gender combinations and levels of social proximity, as presented in Table 9 , Results are very similar as with the entire sample (i.e. that includes matches with strangers). As before, we also look at the marginal effects of social proximity on sharing, presented in Table 10. Panel (a) presents the estimated marginal effects of a friendship tie for the different gender combinations. Here again we find that for F-M dyads the effect of a friendship tie is negative, while it is positive for all other dyads. While this is the case with both dictator and recipient fixed effects, there are some important differences in the estimated size of the marginal effects and its statistical significance. With F-F dyads the marginal effect is statistically significant with both dictator and recipient fixed effects, while with M-F and F-M the effects are only statistically significant with recipient fixed effects.

Panels (b) and (c) present the results of a pairwise comparison of the marginal effects across the different gender combinations, using Models 8 and 9, respectively. With dictator 
Table 10: Marginal effects of social tie (same village sample)

\begin{tabular}{|c|c|c|c|c|}
\hline \multicolumn{5}{|c|}{ (a) Marginal effect by gender combination } \\
\hline & M-M & M-F & $\mathrm{F}-\mathrm{F}$ & F-M \\
\hline $\mathrm{P}(2)$ (dict. FE) & 0.674 & 0.256 & $2.701^{* *}$ & -0.909 \\
\hline $\mathrm{P}(2)$ (rec. FE) & 1.326 & $5.210^{* *}$ & $4.308^{* * *}$ & $-4.770^{* *}$ \\
\hline \multicolumn{5}{|c|}{ (b) Pairwise comparison across gender combinations (dictator $F E)^{\text {a }}$} \\
\hline \multirow{4}{*}{$\mathrm{P}(2)$} & & $\mathrm{M}-\mathrm{F}$ & F-F & F-M \\
\hline & M-M & 0.605 & 0.113 & 0.113 \\
\hline & M-F & & $0.085^{*}$ & 0.302 \\
\hline & F-F & & & $0.012^{* *}$ \\
\hline \multicolumn{5}{|c|}{ (c) Pairwise comparison across gender combinations (recipient FE) a } \\
\hline \multirow{4}{*}{$\mathrm{P}(2)$} & & $\mathrm{M}-\mathrm{F}$ & F-F & $\mathrm{F}-\mathrm{M}$ \\
\hline & M-M & 0.157 & $0.091^{*}$ & $0.025^{* *}$ \\
\hline & M-F & & 0.740 & $0.001^{* * *}$ \\
\hline & F-F & & & $0.000^{* * *}$ \\
\hline
\end{tabular}

Note. Regression results used of Models 8 and 9 of Table $8{ }^{* * *},{ }^{* *},{ }^{*}$ indicate two-sided significance levels of an F-test at 1,5 , and $10 \%$, respectively. ${ }^{a}$ Twosided p-values

fixed effects, the difference of the marginal effect of 'P(2)' between F-F and F-M is statistically significant, and marginally significant between M-F and F-F. With recipient fixed effects, the difference is statistically significant between F-F and each of the other gender combinations. The difference between F-F and M-M is also marginally significant. We summarize the main observations in a new result.

RESULT 3. Within their village, men and women share more with female friends than with female non-friends, but women share less with male friends than with male non-friends. Differences in the marginal effect of a friendship tie are statistically significant between female-male dyads and each of the other gender combinations. With recipient fixed effects and controls for social ties there remains a direct gender effect, with men sharing more than women.

\subsection{Biases in the reporting of friendship ties}

In the analysis of the influence of friendship ties on sharing, so far we ignored potential differences in the individual reporting of these ties. However, it is very common for two persons in a dyad not to coincide in the reporting of a friendship tie between them (see e.g. 
Comola and Fafchamps (2014)). To deal with such lack of concordant reporting we have used OR-ties in the analysis so far, in which we assume there is a friendship tie when at least one of both nodes in a dyad reports such a tie. One of both nodes in a dyad might forget to report a friendship tie and the use of OR-ties corrects this. However, there may be two issues with this assumption. First, there may be gender differences in the reporting of friendship ties, and second, for its influence on sharing behaviour it may matter who reported the tie, i.e. whether the dictator or the recipient reported the tie. If both issues are present, estimates of the effect of friendship ties and its interaction with gender may become biased. We will address both potential issues in the rest of this section.

To assess the first issue, we look at individual reporting of friendship ties. Table 11 reports the frequency of reported ties by gender combination. Column (a) presents these frequencies as proportion of the total number of potential ties. The differences in reported friendship ties are very similar to the differences we observe with OR-ties (see Table 3). Reported friendship ties among men are more common than among women $(22.45 \%$ and $7.44 \%$, respectively), and based on two-tailed t-test the difference is statistically significant (two-sided $\mathrm{p}=0.000) .{ }^{19}$ Friendship ties among men are also more common compared to mixed-gender ties as reported by men (two-sided $\mathrm{p}=0.000$ ), while friendship ties among women are equally likely as mixedgender ties as reported by women (two-sided $\mathrm{p}=0.188$ ). Finally, comparing the reporting of mixed-ties by men and women we observe that men report them equally likely as women do $(6.34 \%$ and $9.92 \%$, respectively, and two-sided $\mathrm{p}=0.160)$. This suggests that there is no gender bias in the reporting of friendship ties.

Table 11: Summary statistics of reported friendship ties

\begin{tabular}{lcccc}
\hline \hline & \multicolumn{2}{c}{ (a) All dyads } & \multicolumn{2}{c}{ (b) Alter reports tie } \\
& freq. & $\mathrm{N}$ & freq. & $\mathrm{N}$ \\
\hline Men - men & $22.45 \%$ & 2,673 & $28.38 \%$ & 444 \\
Men - women & $6.34 \%$ & 2,729 & $11.39 \%$ & 237 \\
Women - women & $7.44 \%$ & 3,443 & $17.54 \%$ & 228 \\
Women - men & $9.92 \%$ & 3,388 & $17.09 \%$ & 158 \\
\hline
\end{tabular}

Column (b) reports the same frequencies but conditional on alter having reported a friendship tie. This allows us to study the extent to which ego and alter agree on having a friendship 
tie. We observe that it is very common for ego not to report a tie when alter does. Looking at same gender dyads, we find that concordant reporting is more common among men than among women. In $28.38 \%$ of the male-male dyads in which alter reports a friendship tie ego also reports such a tie, while with female-female dyads this frequency is only $17.54 \%$. Based on a $\mathrm{t}$-test this difference is statistically significant (two-sided $\mathrm{p}=0.021$ ). Looking at mixed-gender dyads, we observe that men tend to agree somewhat less on the ties reported by women than women agree on the ties reported by men, but that this difference is not statistically significant $(11.39 \%$ versus $17.09 \%$; two-sided $\mathrm{p}=0.269)$. In sum, while we find a similar picture with reported (i.e. non-symmetrized) ties as with OR-ties, we do find gender differences in concordant reporting, which is more frequent among men than among women and mixed-gender dyads.

The second issue is related to the fact that we ignore whether it is the dictator or the recipient who reports the tie, which might matter for its influence on sharing. One might argue that it is actually the tie as perceived by the dictator that matters most for the sharing decisions, which supports the use of ties as reported by the dictator. Others might argue that using ties as reported by the dictator might add measurement error. For example, if the dictator in a pair did not report a tie between them but the recipient did, we would assume such a tie to be absent (in other words, we do not exploit the advantage of using OR-ties). It is expected that the importance of this issue for our analysis increases with gender differences in reporting.

In order to test whether the results reported in section 3.4 are robust to using ties as reported by the dictator, we run the same regressions but with ties as reported by the dictator. We use again the same village sample as the definition of social ties only matters for within village variation in sharing, and by doing so we can again use recipient fixed effects. Table B.1 in the Appendix presents the results. To make comparison easier we estimate marginal effects for each of the gender matchings, as presented in Table 12

In Panel (a) we observe that while the sign of the marginal effects is the same as with OR-ties (compare Table 10), there are differences in the size and statistical significance of the effects in some of the gender combinations. With dictator fixed effects none of the effects are statistically significant, while with recipient fixed effects we observe a much stronger effect with M-F dyads and a much weaker effect with F-F dyads. In Panel (b) we find that with 
Table 12: Marginal effects of tie as reported by dictator

\begin{tabular}{|c|c|c|c|c|}
\hline \multicolumn{5}{|c|}{ (a) Marginal effect by gender combination } \\
\hline & M-M & $\mathrm{M}-\mathrm{F}$ & F-F & F-M \\
\hline $\mathrm{P}(2)$ (dict. FE) & 1.125 & 0.686 & 1.018 & -1.691 \\
\hline $\mathrm{P}(2)$ (rec. FE) & 1.849 & $8.749^{* * *}$ & $1.711^{*}$ & -4.815 \\
\hline \multicolumn{5}{|c|}{ (b) Pairwise comparison across gender combinations (dictator $F E)^{\text {a }}$} \\
\hline \multirow{4}{*}{$\mathrm{P}(2)$} & & $\mathrm{M}-\mathrm{F}$ & $\mathrm{F}-\mathrm{F}$ & F-M \\
\hline & M-M & 0.600 & 0.940 & $0.031^{* *}$ \\
\hline & $\mathrm{M}-\mathrm{F}$ & & 0.806 & $0.046^{* *}$ \\
\hline & F-F & & & $0.026^{* *}$ \\
\hline \multicolumn{5}{|c|}{ (c) Pairwise comparison across gender combinations (recipient FE) a } \\
\hline \multirow{4}{*}{$\mathrm{P}(2)$} & & $\mathrm{M}-\mathrm{F}$ & $\mathrm{F}-\mathrm{F}$ & F-M \\
\hline & M-M & $0.031^{* *}$ & 0.950 & $0.083^{*}$ \\
\hline & $\mathrm{M}-\mathrm{F}$ & & $0.013^{* *}$ & $0.001^{* * *}$ \\
\hline & F-F & & & $0.042^{* *}$ \\
\hline
\end{tabular}

Note. Regression results used of Models 5 and 6 of Table B.1 in the Appendix. Only pairs of the same village used. ${ }^{* * *},{ }^{* *},{ }^{*}$ indicate two-sided significance levels of an F-test at 1, 5, and $10 \%$, respectively. ${ }^{\text {a }}$ Two-sided p-values

dictator fixed effects the marginal effects with F-M are significantly lower compared to each of the other dyads, which was not the case with OR-ties. In Panel (c) we observe that with recipient fixed effects the marginal effect with $\mathrm{M}-\mathrm{F}$ is significantly larger compared with $\mathrm{M}-\mathrm{M}$ and F-F, which was not the case with OR-ties. We summarize the main observations in a new result.

RESULT 4. Gender differences in friendship ties are similar with reported (non-symmetrized) ties and OR-ties, but concordant reporting is more frequent among men than among women and mixed-gender dyads. Social tie effects in sharing are robust to using ties as reported by the dictator instead of OR-ties, but tend to be weaker with the former. One exception are M-F dyads where the effect of friendship ties, as reported by the dictator, has become significantly stronger than in $M-M$ and $F-F$ dyads.

\section{Discussion and conclusion}

In rural areas in developing countries gender inequality tends to be severe which might have serious welfare implications if it determines how scarce economic resources are shared. To better understand the welfare implications of gender inequality, it is important to know how 
gender influences resource sharing and in what ways social ties interact with this influence. To address these questions we elicited for a rural village in Nicaragua the friendship ties among almost all household heads and implemented a series of dictator games played by household heads with other village recipients as well as strangers.

We found that women tend to share less than men, and that this difference is largest when dictator and recipient live in the same village and have different gender. We also found that social ties exert an important influence on sharing and that women have fewer friendship ties within their village than men. Regression analysis showed important gender differences in the effect of social ties on sharing. More specifically, while both men and women share more with female friends than with female non-friends, women share less with male friends than with male non-friends. Finally, we found that with controls for friendship ties and recipient fixed effects, there remains a direct gender effect on within-village sharing, with men sharing more than women.

These results indicate that there are several factors that potentially drive gender differences in sharing. First, the direct gender effect on resource sharing, which remains after controlling for friendship ties, could be related to the gender-specific roles in society and the corresponding responsibilities which translate into a gender difference in preferences for resource sharing. Women's preference for human capital investments may make them share less than men with community members outside their household. This would provide support for the hypothesized gender difference in baseline altruism, if the result were not only observed for the same village sample. The latter suggests that it is not women's preferences that drives this result (as we do not observe any gender difference when paired with strangers), but rather men's larger generosity towards people from the same village.

Second, an alternative explanation for the gender difference in sharing with people from the same village might be the smaller (larger) friendship networks of women (men). We indeed found that friendship ties among women are less common than friendship ties among men, and are equally common as mixed-gender ties. The difference in friendship networks between men and women might then influence their expected sharing, if friendship ties exerted a positive effect on the willingness to share resources, as demonstrated in other experimental stud- 
ies (Leider et al., 2009; Goeree et al., 2010; Brañas-Garza et al., 2010; Ligon and Schechter, 2012). However, comparing the results of regression models with and without controls for friendship ties we did not find any evidence that supports this explanation, at least not at the aggregate level. This is not surprising as with more advanced analyses we found strong differences in the marginal effect of friendship ties across the different gender combinations. While a positive effect of social ties was clearly observed for sharing with women (by both men and women), sharing among men within the same village was less driven by social tie effects, and women shared less with male friends than with non-friends. The latter could be driven by women's belief that male friends would approve - more than male non-friends - if they kept more resources for themselves, which would be spent on household consumption, children, etc. That such deliberation is plausible is supported by the observation that men themselves tend to be more generous to female friends than to male friends. Women thus seem to correctly anticipate the generosity of male friends, by keeping more for themselves when matched with a male friend. ${ }^{20}$

In closing, our results have implications for policies, especially when these distribute resources or new opportunities (such as development aid) via local communities and networks. Our results indicate that the gender and the networks of the actors involved in the distribution of resources can strongly influence actual resource distribution and implied welfare consequences. Women might receive less resources from others as they tend to have smaller networks than men. This effect, however, is counteracted by the fact that friendship ties have a stronger positive effect on the generosity women experience, and that women themselves tend to keep more resources when matched with male friends than with non-friends. As a result, if policy-makers wanted more resources to be spent by women - e.g. because they tend to spend them more on human capital investments -, a potentially effective policy would be to stimulate the formation of mixed-gender ties. 


\section{Notes}

${ }^{1}$ Whereas some studies did not find any gender effect, others found that women tend to be more generous than men (see, e.g., Bolton and Katok, 1995; Eckel and Grossman, 1996, 1998; Cox and Deck, 2006; Konow et al., 2008 and Croson and Gneezy, 2009, for a survey). Evidence on the effect of the recipient's gender on the giver's decision is also mixed. Dufwenberg and Muren (2006) found that men receive less than women and Ben-Ner et al. (2004) found that if the gender of the recipient is known, women tend to give systematically less to women than to men and persons of unknown gender.

${ }^{2}$ Dictator games have been widely used to elicit sharing preferences (see, e.g., Camerer, 2003, chapter 2). In our experiment neither the term dictator or dictator game was used.

${ }^{3}$ Some studies have looked at gender and social pressure exerted by spouses or relatives to share income (Ashraf, 2009; Jakiela and Ozier, 2016). However, with decision-making being private in our experimental set-up, we do not expect social pressure to have any significant influence on sharing.

${ }^{4} \mathrm{We}$ also considered to pay out only one randomly chosen decision, but decided against it because the explanation and implementation of a randomization device would have been very time consuming and may have also raised suspicion in our subjects who did not have any experience with economics experiments.

${ }^{5}$ For a similar design see the one-way identification treatment of Bohnet and Frey (1999).

${ }^{6} \mathrm{We}$ could have opted for a full anonymity design in which only the gender of the recipient is revealed. However, the application of such a design in settings characterized by extreme gender inequality would likely have suffered from an experimenter demand effect. For example, it is likely that with such a design male participants might think that we would appreciate it if they showed generosity towards women who suffer from gender inequality.

${ }^{7}$ We cannot exclude that dictators reveal themselves to the recipients after the experiment. We will discuss the consequences of this in the discussion section.

${ }^{8}$ For more on such social effects in lab-in-the-field experiments, see Castillo and Carter (2003).

${ }^{9}$ For more details on the experimental instructions we refer to Appendix A

${ }^{10}$ Bounded networks are networks with clearly defined boundaries, such as networks within villages and organizations, for which all members are surveyed. For a description of the method see, for instance, the documents section of Jean Ensminger's and Joseph Henrich's Roots of Sociality project website at http://jee.caltech.edu/files/2011/06/Social-Network-Analysis.pdf

${ }^{11}$ Leider et al. (2009) used an incentivised coordination game procedure to elicit friendship ties among Harvard students. We did not adopt their elicitation method as it would be too complicated for our subjects.

${ }^{12}$ In addition to friendship relations we also captured economic relations, neighbour relations, family relations as well as joint participation in social-public activities. In this article, we only make use of the data of friendship ties. 
${ }^{13}$ Bohnet and Frey (1999) and Charness and Gneezy (2008) showed that revealing the identity of the recipient significantly increases dictator giving. Henrich et al. (2005) also observed proposals of more than $50 \%$ in ultimatum game experiments in some of their investigated small-scale societies.

${ }^{14}$ Our success ratio is slightly higher than those of Goeree et al. (2010) and Leider et al. (2009), who report success rates of $77 \%$ and $71 \%$, respectively. Of the missing 23 household heads, only two refused to participate and 21 were not present in the village when we conducted the study.

${ }^{15}$ In doing so we follow the practices of earlier network studies (cf. Leider et al., 2009; Jackson et al., 2012). In section 3.5 we will take a closer look at the implications of this procedure by testing the robustness of our results to the use of the non-symmetrized ties.

${ }^{16}$ In the descriptive analysis we were unable to take the gender of both dictator and recipient into account as we needed a sufficient number of observations for each subcategory to come to meaningful statistical comparisons.

${ }^{17}$ We use the results of Model 5, as the fixed effects in Model 6 make these predictions not estimable.

${ }^{18} \mathrm{~A}$ test of order effects makes most sense with the same village village pairs only, as we do not have any variation with the stranger pair, which was always the first pair. With same village pairs, where people know each other, it is most important to control for observable and unobservable characteristics of the recipient which can be done with recipient fixed effects. Moreover, in the sub-sample of stranger pairs we do not have variation in social ties, which makes that the use of the full sample (including stranger pairs) with recipient fixed effects would force us to drop one of the social tie categories due to collinearity.

${ }^{19}$ Standard errors in all t-tests reported are corrected for multiple responses per ego.

${ }^{20}$ We cannot completely exclude the possibility that dictators revealed themselves to the recipients after our experiment and that this may have influenced their sharing decisions. Assuming that they would only approach recipients if they were generous and if they expected their claims about their sharing to be perceived as credible by the recipients, anticipated reciprocity might have been an additional motive for resource sharing. The weak effect of social ties for within-village sharing among men and the observation that men share more with men in their village than with strangers provides suggestive evidence for this motive. Strangers cannot be approached after the experiment, hence men cannot claim any reciprocity from them; and men might approach friends and non-friends alike, in an attempt to strengthen or build friendship ties, respectively. This option might appeal especially to men, who have higher mobility than women. 


\section{References}

Ado, A. and Kurosaki, T. (2014). Motives for sharing in developing countries: Experimental evidence from jakarta. PRIMCED Discussion Paper Series, No. 53.

Andreoni, J. and Miller, J. (2002). Giving according to garp: An experimental test of the consistency of preferences for altruism. Econometrica, 70(2):pp. 737-753.

Ashraf, N. (2009). Spousal control and intra-household decision making: An experimental study in the philippines. American Economic Review, 99(4):1245-77.

Attanasio, O., Barr, A., Cardenas, J. C., Genicot, G., and Meghir, C. (2012). Risk pooling, risk preferences, and social networks. American Economic Journal: Applied Economics, $4(2): 134-67$.

Bastani, S. (2007). Family comes first: Men's and women's personal networks in Tehran. Social Networks, 29(3):357 - 374.

Ben-Ner, A., Kong, F., and Putterman, L. (2004). Share and share alike? gender-pairing, personality, and cognitive ability as determinants of giving. Journal of Economic Psychology, 25(5):581 - 589 .

Binzel, C. and Fehr, D. (2013). Giving and sorting among friends: Evidence from a lab-in-thefield experiment. Economics Letters, 121(2):214 - 217.

Blackden, C. M. and Wodon, Q. (2006). Gender, time use, and poverty in Sub-Saharan Africa. World Bank working paper, 73.

Bohnet, I. and Frey, B. S. (1999). The sound of silence in prisoner's dilemma and dictator games. Journal of Economic Behavior and Organization, 38(1):43-57.

Bolton, G. E. and Katok, E. (1995). An experimental test for gender differences in beneficent behavior. Economics Letters, 48(34):287 - 292.

Brañas-Garza, P., Cobo-Reyes, R., Espinosa, M. P., Jiménez, N., Kovárík, J., and Ponti, G. (2010). Altruism and social integration. Games and Economic Behavior, 69(2):249-257. 
Camerer, C. F. (2003). Behavioral Game Theory: Experiments in Strategic Interaction. Princeton University Press.

Castillo, M. and Carter, M. (2003). Identifying social effects with economic field experiments. Working paper, Department of Agricultural and Applied Economics, University of Wisonsin.

Charness, G. and Gneezy, U. (2008). What's in a name? Anonymity and social distance in dictator and ultimatum games. Journal of Economic Behavior and Organization, 68(1):2935.

Comola, M. and Fafchamps, M. (2014). Testing unilateral and bilateral link formation. The Economic Journal, 124(579):954-976.

Cox, J. C. and Deck, C. A. (2006). When are women more generous than men? Economic Inquiry, 44(4):587-598.

Croson, R. and Gneezy, U. (2009). Gender differences in preferences. Journal of Economic Literature, 47(2):448-474.

Dufwenberg, M. and Muren, A. (2006). Generosity, anonymity, gender. Journal of Economic Behavior and Organization, 61:42-49.

Dunbar, G. R., Lewbel, A., and Pendakur, K. (2013). Children's resources in collective households: Identification, estimation, and an application to child poverty in malawi. American Economic Review, 103(1):438-71.

Eckel, C. C. and Grossman, P. J. (1996). Altruism in anonymous dictator games. Games and Economic Behavior, 16(2):181-191.

Eckel, C. C. and Grossman, P. J. (1998). Are women less selfish than men? Evidence from dictator experiments. Economic Journal, 108(448):726-735.

Goeree, J. K., McConnell, M. A., Mitchell, T., Tromp, T., and Yariv, L. (2010). The 1/d law of giving. American Economic Journal: Microeconomics, 1(1):183-203. 
Gowdy, J., Iorgulescu, R., and Onyeiwu, S. (2003). Fairness and retaliation in a rural Nigerian village. Journal of Economic Behavior \& Organization, 52(4):469 - 479.

Gurven, M., Zanolini, A., and Schniter, E. (2008). Culture sometimes matters: Intra-cultural variation in pro-social behavior among Tsimane Amerindians. Journal of Economic Behavior \& Organization, 67(34):587 - 607.

Hanson, S. (2010). Gender and mobility: new approaches for informing sustainability. Gender, Place \& Culture, 17(1):5-23.

Henrich, J., Boyd, R., Bowles, S., Camerer, C., Fehr, E., Gintis, H., McElreath, R., Alvard, M., Barr, A., Ensminger, J., Henrich, N. S., Hill, K., Gil-White, F., Gurven, M., Marlowe, F. W., Patton, J. Q., and Tracer, D. (2005). "Economic man" in cross-cultural perspective: Behavioral experiments in 15 small-scale societies. Behavioral and Brain Sciences, 28:795815.

Hoddinott, J. and Haddad, L. (1995). Does female income share influence household expenditures? evidence from Cte d'Ivoir. Oxford Bulletin of Economics and Statistics, 57(1):77-96.

Jackson, M. O., Rodriguez-Barraquer, T., and Tan, X. (2012). Social capital and social quilts: Network patterns of favor exchange. American Economic Review, 102:1857-1897.

Jakiela, P. (2011). Social preferences and fairness norms as informal institutions: Experimental evidence. American Economic Review, 101(3):509-13.

Jakiela, P. and Ozier, O. (2016). Does africa need a rotten kin theorem? experimental evidence from village economies. The Review of Economic Studies, 83(1):231-268.

Kennedy, E. and Peters, P. (1992). Household food security and child nutrition: the interaction of income and gender of household head. World Development, 20(8):1077 - 1085.

Konow, J., Saijo, T., and Akai, K. (2008). Morals and mores? Experimental evidence on equity and equality from the US and Japan. Technical report, Institute of Social and Economic Research, Osaka University. 
Leider, S., Mobius, M. M., Rosenblat, T., and Do, Q.-A. (2007). How much is a friend worth? directed altruism and enforced reciprocity in social networks.

Leider, S., Möbius, M. M., Rosenblat, T., and Do, Q.-A. (2009). Directed altruism and enforced reciprocity in social networks. Quarterly Journal of Economics, 124(4):1815-1851.

Ligon, E. and Schechter, L. (2012). Motives for sharing in social networks. Journal of Development Economics, 99(1):13 - 26.

Mandel, J. L. (2006). Creating profitable livelihoods: Mobility as a practical and strategic gender need in Porto Novo, Benin. Journal of Economic and Social Geography, 97(4):343363.

Marsden, P. V. (1987). Core discussion networks of Americans. American Sociological Review, 52(1):pp. 122-131.

McPherson, M., Smith-Lovin, L., and Cook, J. M. (2001). Birds of a feather: Homophily in social networks. Annual Review of Sociology, 27:415-444.

Phipps, S. A. and Burton, P. S. (1998). Whats mine is yours? the influence of male and female incomes on patterns of household expenditure. Economica, 65(260):599-613.

Stehl, J., Charbonnier, F., Picard, T., Cattuto, C., and Barrat, A. (2013). Gender homophily from spatial behavior in a primary school: A sociometric study. Social Networks, 35(4):604 $-613$.

Thomas, D. (1990). Intra-household resource allocation: An inferential approach. Journal of Human Resources, 25(4):635-664.

Thomas, D. (1993). The distribution of income and expenditure within the household. Annales d'conomie et de Statistique, (29):109-135.

Wellman, B. (2007). The network is personal: Introduction to a special issue of social networks. Social Networks, 29(3):349-356. 
World Bank (2012). Gender Equality and Development. World Development Report 2012. World Bank.

Yoong, J., Rabinovich, L., and Diepeveen, S. (2012). The impact of economic resource transfers to women versus men. a systematic review. Technical report, London: EPPI-Centre, Social Science Research Unit, Institute of Education, University of London. 


\section{Appendix}

\section{A. Experimental Instructions}

The experimental instructions are originally in Spanish; text between [ ] are instructions for the experimenter assistant.

We now ask you to participate in an experiment in which you can earn money. The amount of money you earn is yours, whatever the amount is.

Soon I will give you 20 coins of 1 Córdoba and you will be free to divide this amount between yourself and another person. For this, we use this small black box [show the box]. In this box, you will find 20 coins of 1 Córdoba [open the box and show the 20 coins]. You are allowed to take as many coins as you wish. The coins you leave in the box will be given to another person. In particular, we ask you to do the following:

1. Take the number of coins you want to keep out of the box and leave in the box the coins you want to give to the other person.

2. Refill the box with these small rings [show metal rings] and put the lid on the box. In this way, I will not be able to see how many coins you will have left in the box, nor can I get an idea about it through the weight of the box. The weight of the box will always be the same whatever the amount of coins you leave in the box.

Thereafter, we put a sticker on the box with the name of the person who will get the coins and we put some tape on it to seal the box. I will give the box to my supervisor, who waits at the car and who will bring the coins to the other person. Note that you will know the identity of the other person, whereas that other person will NOT know your identity.

I will now give you some arbitrary examples for further clarification. [Take the coins of one of the boxes and use them for the examples].

1. You have here 20 coins of 1 Córdoba. Imagine that you decide to take 2 coins out of the box. How many coins will the other person receive? (20 minus 2 equals 18)

2. I will give you another example. Imagine that you decide to take 10 coins out of the box. How many coins will the other person receive? (20 minus 10 equals 10) 
3. I will give you a final example. Imagine that you decide to take 20 coins out of the box. How many coins will the other person receive? (20 minus 20 equals 0 ).

We will repeat this experiment 6 times. Each time, you will be able to take coins and leave coins for the other person, who will each time be a different one. Thus, I will give you 6 boxes of 20 coins to divide between yourself and another person. Each time, this person will be a different one. The first time you will divide the 20 coins with someone from another village in this region. You will not know this person. The other 5 times you will divide 20 coins with someone from your community. Once again, note that this other person will NOT know your identity.

To select the five persons of your community, I will ask you to take small cards from this bag. Each card has a different number, and each number corresponds to a different person in the community. After having taken a number, I will look up this number on a list and tell you the name of that person. Thereafter, I will give you a box with coins, so that you can decide on the number of coins you keep and how many you give to the other person. When taking this decision, I will give you privacy. You can go inside your house, [if this is not possible, say: I will turn my back so that I will be unable to know your decision; give me a signal when you are ready]. Please do not tell me the decision you will make or you have taken.

After having taken your decision and having closed the box we will seal the box, and you are not allowed any more to change your decision. Thereafter, we will draw another number from the bag and I will ask you to take the next decision. [Ask whether the participant has any questions, and clarify any doubts if needed. If there are no further questions, start with the first decision.] 


\section{B. Additional results}

Table B.1: Determinants of sharing - alternative definitions of tie

\begin{tabular}{lcccccc}
\hline \hline & & a. OR-tie & \multicolumn{4}{c}{ b. tie reported by dict. } \\
& $(1)$ & $(2)$ & $(3)$ & $(4)$ & $(5)$ & $(6)$ \\
Male (dict.) & 1.407 & & $2.022^{* *}$ & 1.085 & & $1.811^{* *}$ \\
& $(1.241)$ & & $(0.888)$ & $(1.211)$ & & $(0.846)$ \\
Male (rec.) & -0.099 & -0.292 & & -0.566 & -0.611 & \\
& $(0.675)$ & $(0.596)$ & & $(0.651)$ & $(0.549)$ & \\
Male (dict.) $\times$ Male (rec.) & 0.092 & 0.721 & -1.320 & 0.655 & 1.034 & -0.819 \\
& $(0.909)$ & $(0.789)$ & $(1.512)$ & $(0.868)$ & $(0.711)$ & $(1.348)$ \\
$\mathrm{P}(2)$ & $2.904^{* * * *}$ & $2.701^{* *}$ & $4.308^{* * *}$ & $2.103^{*}$ & 1.018 & $1.711^{*}$ \\
& $(1.066)$ & $(1.165)$ & $(0.889)$ & $(1.080)$ & $(1.220)$ & $(0.896)$ \\
Male (dict.) $\times \mathrm{P}(2)$ & 0.048 & $-2.445^{*}$ & 0.902 & $4.102^{* * *}$ & -0.332 & $7.038^{* * *}$ \\
& $(1.927)$ & $(1.392)$ & $(2.705)$ & $(1.817)$ & $(1.346)$ & $(2.776)$ \\
Male (rec.) $\times \mathrm{P}(2)$ & $-7.643^{* * *}$ & $-3.610^{* *}$ & $-9.078^{* * *}$ & $-7.387^{* * *}$ & $-2.709^{* *}$ & $-6.527^{* *}$ \\
& $(1.971)$ & $(1.389)$ & $(2.099)$ & $(2.488)$ & $(1.187)$ & $(3.166)$ \\
Male (dict.) $\times$ Male (rec.) $\times \mathrm{P}(2)$ & $5.855^{* *}$ & $4.028^{* *}$ & 5.195 & 2.801 & $3.149^{* *}$ & -0.373 \\
& $(2.449)$ & $(1.626)$ & $(3.793)$ & $(2.910)$ & $(1.478)$ & $(4.762)$ \\
Constant & $9.140^{* * * *}$ & $9.827^{* * *}$ & $8.655^{* * *}$ & $9.477^{* * *}$ & $10.054^{* * *}$ & $9.052^{* * * *}$ \\
& $(0.969)$ & $(0.398)$ & $(0.789)$ & $(0.934)$ & $(0.395)$ & $(0.761)$ \\
\hline Observations & 285 & 285 & 285 & 282 & 282 & 282 \\
$R^{2}$ & 0.108 & 0.077 & 0.140 & 0.117 & 0.053 & 0.135 \\
$\mathrm{~F}$ & 3.641 & 4.047 & 5.932 & 5.728 & 5.500 & 4.027 \\
\hline \hline
\end{tabular}

Notes: OLS regression. ${ }^{* * *},{ }^{* *},{ }^{*}$ indicate two-sided significance levels at 1,5 , and $10 \%$, respectively; standard errors (in parentheses) clustered at the dictator level, except models 3, 6 and 9 in which they are clustered at the recipient level. Controls used for order effects. 